\title{
PERRIN, Burt y TYRRELL, Tony (eds.): Changing bureaucracies: adapting to uncertainty, and how evaluation can help
}

\section{PERRIN, Burt \& TYRRELL, Tony (eds.): Changing bureaucracies: adapting to uncertainty, and how evaluation can help}

\author{
Osvaldo Feinstein \\ Universidad Complutense de Madrid (España) \\ ORCID: https://orcid.org/0000-0001-6144-0614 \\ ofeinstein@yahoo.com
}

\begin{abstract}
NOTA BIOGRÁFICA
Profesor en el Máster en Evaluación de Programas y Políticas Públicas de la Universidad Complutense de Madrid. Autor y editor de libros y artículos sobre evaluación y desarrollo. Ha sido profesor en varias universidades e instituciones europeas y latinoamericanas, incluyendo la Maestría en Estudios de Desarrollo de la Facultad Latinoamericana de Ciencias Sociales (FLACSO/Ecuador), el programa de desarrollo profesional de la Sociedad Europea de Evaluación (EES) y el Instituto Europeo de Administración Pública (EIPA). Fue asesor y gerente en el Departamento de Evaluación del Banco Mundial y evaluador principal del Fondo Internacional de Desarrollo Agrícola (FIDA) de Naciones Unidas.
\end{abstract}

\section{RESUMEN}

Recensión: Perrin, Burt y TYrRell, Tony (eds.): Changing bureaucracies: adapting to uncertainty, and how evaluation can help. New York, Estados Unidos: Routledge, 2021, 220 págs.

\section{PALABRAS CLAVE}

Evaluación; Burocracias; Adaptación; Transformación.

\begin{abstract}
Review: Perrin, Burt \& TYrRell, Tony (eds.): Changing bureaucracies: adapting to uncertainty, and how evaluation can help. New York, Estados Unidos: Routledge, 2021, 220 pp.
\end{abstract}

\section{KEYWORDS}

Evaluation; Bureaucracies; Adaptation; Transformation.

Este libro trata sobre la relación entre burocracias y evaluadores, analizando y sintetizando experiencias correspondientes a contextos diversos (organismos internacionales, gobiernos, y, en menor medida, sector privado; la mayor parte de los casos considerados son europeos, además de un capítulo sobre Nueva Zelanda y otro sobre África). Los autores son evaluadores con una amplia experiencia.

El volumen está estructurado en tres partes: I) Trabajando dentro de las restricciones burocráticas, II) El apoyo de la evaluación a las burocracias y III) Desafíos para un papel significativo de la evaluación. Cada parte incluye cuatro capítulos en los cuales se identifican problemas y se proponen soluciones. 
Si bien el libro está focalizado en el aprendizaje de las organizaciones y el aporte que la evaluación puede realizar al mismo, también se incluyen algunas discusiones sobre «accountability» (responsabilización/ rendición de cuentas), y sobre la relación entre aprendizaje y rendición de cuentas.

Los autores plantean que en un mundo donde prevalece la incertidumbre las burocracias deben adaptarse y que la evaluación puede contribuir a la adaptación. Pero también indican que hay varios escollos que superar para que la evaluación no se burocratice. Con base en estudios de caso, revisión de la literatura y entrevistas a evaluadores experimentados, destilan lecciones de la experiencia.

Cabe señalar que ha comenzado recientemente a desarrollarse un enfoque más ambicioso de la evaluación que no se limita a la adaptación sino que aspira contribuir a la transformación de la sociedad. Mientras que el enfoque adaptativo, como el empleado por la mayor parte de los autores de esta obra, puede contribuir a la microevolución, el enfoque transformativo apunta al cambio estructural, sistémico.

A pesar de la limitación señalada, este libro, adecuadamente compilado por Burt Perrin y Tony Tyrrell, puede ser muy útil para administradores públicos y particularmente para evaluadores de políticas públicas, programas y proyectos, con el propósito de mejorar el funcionamiento de las burocracias para que respondan más apropiadamente a las demandas ciudadanas. 